\title{
A EDUCAÇÃO DO CORPO E O PROCESSO CIVILIZATÓRIO: A FORMAÇÃO DE "ESTÁTUAS PENSANTES"
}

\author{
Dnda. Rubia-mar Nunes Pinto
}

Faculdade de Educação Física/UFG

\section{Resumo}

O texto busca realizar um resgate histórico da relação indivíduo, sociedade e corpo na Modernidade a partir das concepções do sociólogo Norbert Elias (1897-1990). Pretendo demonstrar como educação do corpo, especialmente na infância, se apresenta como o contexto privilegiado para o processo civilizatório, a qual impõe, aos indivíduos das sociedades urbanizadas, o exercício de um intenso autocontrole das pulsões e necessidades corporais. $\mathrm{O}$ enfoque recai nas conseqüências advindas, para a vida individual e social, da compreensão do ser humano como ser cindido em exteriorinterior, corpo-mente.

Palavras-Chave: Corpo; Indivíduo; Sociedade.

A palavra corpo é tão freqüente no contexto da vida moderna que aparentemente todos compreendem seu significado. É como uma moeda "cujo valor fosse conhecido e cujo conteúdo já não precisasse ser testado" (Elias, 1994, p. 13). Como substância material e finita do humano, o corpo parece não requerer dos seres humanos processos mais sofisticados de reflexão e a reconstrução, no pensamento, da realidade vivenciada pelas pessoas com e em seus corpos parece extremamente fácil, o que faz com que essa temática seja banalizada no contexto das relações sociais.

A evidência do corpo em nossos dias ao contrário de suscitar procuras no sentido de compreender o significado da corporalidade na formação do indivíduo tem, contraditoriamente, servido a sua banalização a partir da noção que, pertencente ao domínio da natureza, a dimensão corporal é algo pouco complexo e importante no contexto da vida social ${ }^{1}$. Não é sem motivo, entretanto, essa contradição se configura. Tema privilegiado pela Modernidade, o corpo transformou-se em objeto de estudo da ciência e foi tomado como objeto suscetível ao conhecimento e à intervenção humana,

\footnotetext{
${ }^{1}$ SILVA, A. M., Corpo, ciência e mercado, Campinas: Autores Associados, 2001. - É evidente que as preocupações com a saúde e, atualmente, com a aparência constroem um contexto de cuidados e atenção ao corpo. Neste sentido, ele é alimentado e higienizado tendo em vista a manutenção de sua boa forma. A idéia aqui subjacente é do corpo restrito ao seu aspecto biológico cuja metáfora mais comum é a sua comparação com as máquinas, em sentido bastante próximo ao que já havia se manifestado em Descartes.
} 
estando sujeito ao esquadrinhamento de suas possibilidades, à modificação de suas formas, à ampliação de seus limites históricos.

O corpo é também objeto de um culto de base narcisista ${ }^{2}$, a corpolatria, que no contexto da vida cotidiana provoca também uma explosão que pode ser percebida na exuberância das técnicas ligadas ao vestuário, à dança, ao teatro, aos esportes, ao mundo do trabalho, às práticas alternativas de saúde, alimentação e higiene, entre outras. A corpolatria tem ensejado a produção de uma imensa diversidade de aparatos máquinas, produtos, técnicas - ligados aos cuidados e à manutenção de uma aparência padronizada a partir dos ditames de certos setores produtivos, como é o caso da indústria da moda.

Procura-se, assim, imprimir ao corpo características inusitadas, rótulos, marcas que o ligam muito mais a um sistema mercadológico do que a um pertencimento cultural. Aliás, a pertença ${ }^{3}$, muitas vezes ressaltada nos traços físicos e nas formas corporais como a cor da pele, cabelos e olhos, peso, altura, entre outros - mas também em toda uma rede de gestos, posturas, ritmos - quando não é condizente com certos ditames ideologicamente constituídos é, crescentemente, negada e em seu lugar outros sinais de pertencimento, mais adequados a estes ditames, são comprados e anexados ao corpo. Repleta dos sentidos e significados de seu tempo, a poesia de Drummond (1984) retrata essa nova identidade.

Em minha calça está grudado um nome/que não é meu de batismo ou cartório,/um nome [...] estranho./Meu blusão traz lembrete de bebida/que jamais pus na boca, nesta vida./Em minha camiseta, a marca do cigarro/que não fumo, até hoje não fumei./ [...] Estou na moda.[...]/Com que inocência demito-me de ser/eu que antes era e sabia/tão diverso de outros, tão mim-mesmo,/ser pensante, sentinte e solidário/com outros seres diversos e conscientes/de sua humana, invencível condição [...] /Onde terei jogado fora/meu gosto e capacidade de escolher,/minhas idiossincrasias tão pessoais,/tão minhas que no rosto se espelhavam,/e cada gesto, cada olhar,/cada vinco da roupa/resumia uma estética?/Por me ostentar assim, tão orgulhoso/de não ser eu, mas artigo industrial/peço que

${ }^{2}$ A respeito ver SENNETT apud SILVA, A. M. Corpo, ciência e mercado, Campinas: Autores Associados, 2001, p. 84. - Narcisismo aqui não deve ser entendido no mesmo sentido que na acepção popular - "amor pela própria beleza" - mas no seu sentido clínico, como uma obsessão que "impede alguém de entender aquilo que é inerente ao domínio do eu e da autogratificação e aquilo que não lhe é inerente".

${ }^{3}$ GEERTZ, C. A interpretação da cultura, Rio de Janeiro: Guanabara Koogan, 1978. 
meu nome retifiquem./Já não me convém o título de homem./Meu novo nome é coisa./Eu sou a coisa, coisamente.

O corpo, afinal, é apresentado como a principal via para a obtenção do prazer individual e para a aprovação social, o que o traduz como cerne da identidade do indivíduo e o transforma, igualmente, em fonte de desassossegos e preocupações. É aqui que se percebe um paradoxo nas intenções e no movimento da luta de forças e interesses: se de um lado, a exposição do corpo se intensifica e parece central, de outro, a corporalidade é desvalorizada e pouco se reflete sobre sua importância. Mesmo evidenciando o corpo, os indivíduos constroem sua autoimagem com base na capacidade de racionalizar atribuindo à substância material um papel secundário em um processo de constituição de indivíduos cindidos em corpo e mente, exterior e interior. Nesse contexto, as idéias de juventude, beleza e felicidade possuindo, atualmente, uma profunda ligação com o corpo trazem a necessidade intensa e urgente de elaborar e efetivar cuidados a ele dirigidos e de educa-lo, adequando-o a padrões éticos e estéticos coerentes com o modelo social vigente.

Tais contradições e paradoxos também revelam, de um ponto de vista crítico, que a sociedade ocidental moderna reflete muito pouco sobre o conteúdo do que se pensa sobre o corpo e sobre as motivações que impulsionam as práticas e discursos referentes a ele. O corpo é visto como uma evidência que acompanha todos os seres humanos - do nascimento à morte - sendo que o seu valor, geralmente, é permeado pelo olhar racional. Marcada por um tipo de racionalidade que sempre busca a utilidade de coisas, objetos e pessoas, a sociedade ocidental parece pensar a corporalidade somente para saber qual é o seu valor utilitário.

Mas afinal, como Silva (2001A) chama a atenção, não é intrigante que em uma sociedade cujos membros percebem-se como seres eminentemente racionais assista-se a um interesse tão intenso pelas questões relativas ao corpo? As possíveis respostas a essa questão devem ser balizadas, em primeiro lugar, pela compreensão que a banalização do corpo que ocorre, simultaneamente, à sua evidência em nossa realidade é um fenômeno social e político de amplo significado e que tem especial importância para o campo educativo. Como implicação direta dessa compreensão surge a necessidade de desvendarmos o processo civilizatório que designou a corporalidade um aparente papel 
secundário na configuração dos indivíduos e da sociedade no período conhecido como Modernidade definindo, de forma mais precisa, o papel da escolarização na produção do corpo educado.

Qual a relação, seria uma questão central, entre a visão do homem como ser cindido em corpo-alma e a forma particular de individualidade que emerge a partir do século XVI e se fortalece nos última duzentos anos? Em que sentido a educação da corporalidade com base na dualidade corpo/mente promove a apreensão de comportamentos e atitudes necessárias e adequadas a vida moderna? É preciso compreender, afinal, os significados que podem ser agregados à educação corporal nos moldes modernos a partir da reflexão acerca dos eventos, idéias e práticas que vem inspirando a idéia do corpo educado. Tal reflexão deve guiar-se pela necessidade de compreender as conseqüências, para a vida social e individual, que advém da percepção dos seres humanos como seres divididos em cogitans e extensa?

Tal visão dualista - que atribui à substância pensante a essência humana relegando o corpo ao segundo plano na definição da imagem que cada indivíduo constrói de si e dos outros - encontra-se em plena expansão e aprofundamento repercutindo, amplamente, na construção e consolidação de relações humanas marcadas pelo distanciamento progressivo do outro e até de si mesmo. Se atualmente assistimos a uma proliferação de práticas e discursos sobre o corpo, os quais se desenvolvem, simultaneamente, a um processo de aprofundamento da nossa consciência como seres racionais, é preciso um esforço no sentido de compreender os desdobramentos de forma particular de autoconsciência para a organização social e, em particular, para as relações que ocorrem entre os indivíduos e entre estes e a natureza.

Para abordar o desenvolvimento das questões relativas ao papel político da corporalidade e seu significado nas relações sociais, recorro às concepções de Norbert Elias acerca do processo civilizatório e da relação indivíduo/sociedade destacando o lugar atribuído à substância corporal do ser humano. Em especial, no livro $A$ sociedade dos indivíduos (1994), o sociólogo alemão traça um panorama do processo de emergência do indivíduo, sujeito do conhecimento, como ser consciente de si a partir das possibilidades dadas pela capacidade de racionalizar, ou seja, como ser capaz de saber-se pensando. Nessa concepção, a autoimagem e/ou autoconsciência do homem 
moderno é a de um ser que tem acesso ao conhecimento através da observação e do pensamento e nunca através da corporalidade.

A análise do autor prima, então, pela discussão sobre a formação do indivíduo singular no interior das formações sociais modernas e, em particular, pelo estabelecimento de confrontos e identidades entre as questões e problemáticas colocadas pela teoria do conhecimento e aquelas decorrentes da relação sociedade/indivíduo.

\section{A Construção Histórica da Relação Indivíduo: sociedade e corpo}

De acordo com Elias (1994), devemos, primeiramente, reconhecer que a forma de autoconsciência que, hoje, é hegemônica na definição do homem moderno não pode ser entendida em separado da situação social daqueles que se vêem desta maneira. Ademais, é preciso entender as formas de consciência e imagem de si que sustentaram a ação e o pensamento humano em outros períodos históricos.

É possível reconhecer [...] que há e houve outras maneiras de vivenciarmos a nós mesmos e aos outros. Podemos dizer que as formas que conhecemos de autoconsciência, a imagem que fazemos do homem, tiveram uma emergência tardia na história da humanidade, começando lentamente e por um breve período se limitando a pequenos círculos da sociedade antiga, para depois, no chamado Renascimento, afetar as sociedades ocidentais. (ELIAS, 1994, p. 81).

Elias (1994) destaca que essa forma particular de autoconsciência e/ou autoimagem é resultante da inserção do indivíduo no interior do processo de civilização que transformou a sociedade medieval na sociedade moderna. O processo civilizatório ocidental desenvolveu, com mais intensidade a noção que o ser humano possui um mundo interior (alma/mente/espírito) que vive em isolamento, apartado do mundo exterior (sociedade, natureza) o que resulta como conseqüência a valorização do indivíduo que vive, permanentemente, a sensação de isolamento e solidão, tão típicas dos dias atuais (ELIAS, 1994). Nesse sentido, o corpo e a gestualidade são cada vez mais conhecidos em suas particularidades e, ao mesmo tempo, ignorados quanto ao seu significado para e nas relações e interações sociais, assumindo uma posição privilegiada 
na produção do indivíduo adaptado à vida urbana e, em dimensão mais ampla, ao sistema produtivo-econômico capitalista.

Conforme Norbert Elias (1994), a problemática da relação indivíduo/sociedade, na sociedade moderna, esbarra constantemente em questões colocadas pelas teorias do conhecimento sendo que é no interior dessas dimensões que podemos vislumbrar o papel que historicamente vem sendo construído para a corporalidade. A pergunta como conhecemos? ou ainda, qual é a origem do conhecimento $?^{4}$ e as respostas que a elas têm sido construídas apresentam como ponto de partida a forma de autoimagem e/ou autoconsciência típica da Modernidade e que está relacionada ao processo de uma crescente individualização na qual o indivíduo percebe-se como indivíduo cujo mundo interior é reprimido pelo mundo externo, esse quase sempre identificado com a sociedade.

A problemática do conhecimento, entretanto, apresenta-se apenas como uma das várias faces que compõem a formação do ser humano. Ocorre que o processo de individualização é visto, contraditoriamente, também como um processo civilizatório que anuncia, a partir da idéia de progresso, a ampliação das possibilidades de vida dos seres humanos, perspectiva essa a ser alcançada pelos avanços científicos e tecnológicos. Um dos aspectos da ampliação dessas possibilidades diz respeito ao crescente conhecimento, domínio e exploração dos fenômenos naturais que, atualmente, vem colocando em risco a própria sobrevivência da humanidade por estar justificado em termos da produção de excedentes e de lucro.

A natureza que em outros momentos históricos significou opressão, perigo e medo, perde aos poucos seu caráter ameaçador e deixa de ser vista como algo que oprime o indivíduo. A natureza tem sido crescentemente despojada de seus mistérios tornando-se como que corriqueira. Os fenômenos naturais estão ou logo estarão completamente dominados - eis a percepção confortadora - e, então, a natureza não é mais vista como uma força opressora ao eu individual. Ao contrário, em sua concepção

\footnotetext{
${ }^{4}$ Conforme GUIRALDELli JR., P. O que é pedagogia. São Paulo: Brasiliense, 1996 - para os gregos, que superavam a explicações mitológicas, a pergunta é $O$ que é o real? para a qual obtiveram uma dupla resposta: uma, inaugura a filosofia como cosmologia, diz que o real é a physis (a natureza); a segunda, traçando os rumos da filosofia como ontologia e metafísica, responde o real é o ser (a essência).
} 
moderna a natureza aparece constantemente como uma pessoa amistosa, que tem seus caprichos e mostra de vez em quando sua imprevisibilidade, mas que é símbolo de autenticidade, bondade e saúde. Assim percebida, a natureza é incorporada à estrutura de personalidade dos indivíduos modernos como algo associado a um suposto eu interior e não mais pertencente ao mundo externo que, por sua vez, é percebido como ameaçador e perigoso.

Essa percepção, ao levar a uma redução da sensação de estranhamento frente à natureza, porém, torna mais perceptíveis as dificuldades enfrentadas pelos indivíduos em processos de difícil controle como aqueles ligados às relações entre as pessoas e os grupos (ELIAS, 1994). Se de um lado, tudo que sob o rótulo natural e apresentado como oriundo da natureza é tomado como sinônimo de perfeição e generosidade, de outro, a sociedade é cada vez mais vista como "aquilo que impede as pessoas de desfrutarem uma vida natural ou autêntica" (ELIAS, 1994, p. 107). Em outras palavras, o controle dos fenômenos naturais que é típico de nosso tempo e também a simultânea percepção dos riscos decorrentes desse controle, fazem com que a natureza seja vista em associação ao $e u$ interior do indivíduo - na condição simultânea de amiga generosa e vítima carente de proteção - e não mais como opositora do mundo externo.

Enquanto força controlada, a natureza é sentida/compreendida como dimensão em que o $e u$ pode expressar-se livremente. Em contrapartida, a inserção dos indivíduos no contexto das relações sociais - sobre o qual se tem pouco ou nenhum controle apresenta-se repleta de conflitos e dilemas, levando a pessoa a perceber-se como um $\mathrm{eu}$ isolado. No interior das relações em sociedade, freqüentemente, o indivíduo isolado aprende a conter seus impulsos imediatos e refrear (dentro de si? de seu corpo?) tudo aquilo que diz respeito ao que considera seu verdadeiro eu. Como resultado dessa dinâmica, aprofunda-se um abismo entre o indivíduo e a sociedade enquanto se reduz a distância entre indivíduo e natureza. Neste sentido, a sociedade e a natureza são vistas pelo indivíduo como forças, eminentemente, diferentes. Uma oprime, a outra liberta. Uma proíbe enquanto a outra permite a plena expressão e realização do ser humano.

Dessa forma consideradas, as duas dimensões são incorporadas pelas pessoas não apenas em uma abstrata estrutura de pensamento -, mas igualmente em sua estrutura emocional. O que a princípio aparece tão somente como uma questão 
associada à capacidade racional e à possibilidade de obter conhecimento expande-se pela totalidade da pessoa deslocando-se daquilo que considera a
"razão", como traço distintivo do "eu" interior separado do mundo "externo", para algo que, na verdade, é apenas a reificação da mesma coisa numa base mais ampla: "a vida inteira", a "existência" do ser humano. Nesse campo ampliado da sociedade, não é incomum depararmos com auto-imagens em que a idéia do eu interior se baseia não apenas nas funções intelectuais, mas também nos sentimentos, na "verdadeira natureza" da pessoa inteira, inclusive nos aspectos mais animais do ser humano, à medida que estes vão sendo crescentemente privatizados. (ELIAS, 1994, p. 107).

A autoconsciência que resulta desse processo, por mais que seja legítima e verdadeiramente expresse a atual estrutura da personalidade de seres humanos apresenta-se, na realidade social concreta, como uma barreira que pode impedir a construção e consolidação de novas relações entre os homens e entre esses e as coisas do mundo (ELIAS, 1994). A antítese no qual se funda a autoconsciência do ser humano moderno - dentro/fora, interior/exterior, mente/corpo - impondo a idéia de que o indivíduo tem um eu interior isolado por um muro invisível do mundo externo é sentida e vivida muito mais como um abismo entre o indivíduo e a sociedade do que entre este e a natureza.

A percepção deste abismo, que é decorrente da consciência que os homens e mulheres modernos têm de si e que é apreendida no desenvolvimento de cada um, é visto, porém, como algo que é natural, no sentido em que não é algo histórico e socialmente construído. Essa forma de autoconsciência ou autoimagem está, de tal maneira, cristalizada em nossa estrutura conceitual e emocional que nos parece impossível a existência de outros modos de ver-se e pensar-se.

Norbert Elias (1994) afirma que a autoimagem e/ou autoconsciência é a resultante dos modos e das condições de vida na sociedade onde cada indivíduo está inserido - e não está dependente apenas das capacidades de cada um - como também está condicionada ao estado de conhecimento daquela sociedade, não sendo, portanto, algo natural e universalmente válido. A autoimagem e/ou autoconsciência é um conceito relacionado aos modos como vemos e/ou compreendemos a nós mesmos, às maneiras através das quais nos definimos no interior da sociedade e na relação conosco 
mesmo, com a natureza e com os outros. Ela não está dada a priori, nem mesmo é eterna e perene, ao contrário, altera-se - às vezes radicalmente - conforme mudam as condições da vida social ao longo do processo civilizatório.

Nessa perspectiva, a autoimagem que possuímos é de seres capazes de compreender, julgar e decidir exclusivamente por seu pensamento e observação individuais, o que expõe um papel secundário à dimensão corporal e as relações sociais na definição desse tipo de consciência. Paradoxalmente, o investimento - científico, político, econômico - no corpo não é (ou foi) suficiente para eleva-lo ao primeiro plano da consciência do ser humano. Apesar de tamanho interesse pela corporalidade, nossa autoimagem parece radicar-se nas possibilidades de conhecimento intelectual. É como se fosse unicamente a razão que nos qualifica enquanto indivíduos e que unicamente a possibilidade de obter e usar, racionalmente, o conhecimento é que nos habilita à vivência social.

A imagem do homem como ser, por excelência, racional surge e desenvolve-se como sintoma e fator de transformações profundas que se deram a partir da transição ${ }^{5}$ da Idade Média para a Modernidade. Ocorreram, então, profundas transformações na estrutura social, na formação e posicionamento dos indivíduos no interior dessa estrutura e nas relações do homem consigo mesmo, com os outros homens e com a natureza. A emergência desta autoimagem relaciona-se, portanto, a mudanças específicas, ainda que amplas, que afetaram todas as relações de vida e poder nas sociedades urbanas ocidentais.

Ela estabeleceu um paralelo com a transição de uma consciência mais "externa", dependente das autoridades, para uma consciência mais autônoma e "individual". Em retrospectiva, podemos ver com maior clareza quão

\footnotetext{
${ }^{5}$ SEVCENKO, N. O renascimento. São Paulo: Atual, 1986 - Muito embora essa transição tenha desenvolvido-se, lentamente, desde o século XI, estamos tomando como referência para o ordenamento de nossa reflexão, os eventos, acontecimentos, práticas e discursos que emergiram, principalmente, nos séculos XVI e XVII na Europa. Neste sentido, é importante referir-se às elaborações de Copérnico, Galileu e Newton acerca dos fenômenos naturais, às descobertas de novas terras e povos, a intensificação do movimento comercial que fortalece uma nova classe social (a burguesia), fragilizando, em contrapartida, aqueles que detinham o poder econômico e político sem nos esquecermos da ruptura conceitual provocada pelos filósofos e artistas humanistas, que resgataram valores da cultura clássica no Renascimento.
} 
estreitamente essa nova forma de autoconsciência, esteve ligada à comercialização crescente e à formação dos estados, à ascensão de ricas classes aristocráticas e urbanas, e não menos importante, ao poder visivelmente crescente dos seres humanos sobre os fenômenos naturais não-humanos (ELIAS, 1994, p. 85)

No contexto das transformações das condições materiais de vida naquele período de transição percebe-se a gênese da constituição de uma nova maneira dos homens encararem a si próprios. Durante todo o período medieval, a autoconsciência humana, alicerçada no cristianismo, era de seres constituídos de natureza e essência divina, dependentes de autoridades ${ }^{6}$ que revelavam a vontade de Deus. O corpo, nesse contexto, embora associado à idéia de pecado e sendo mortificado para a purificação da alma, não era considerado um mero objeto a ser manipulado e alterado em sua materialidade; ele era tido como parte de um universo de criação divina, imerso no mistério da natureza; um microcosmo no seio do macrocosmo.

Soares (2002) lembra que a cultura popular da Idade Média e do Renascimento é pródiga em vivências que têm no corpo o agente principal. A arte circense e a literatura - especialmente Rabelais -, por exemplo, produzem imagens onde

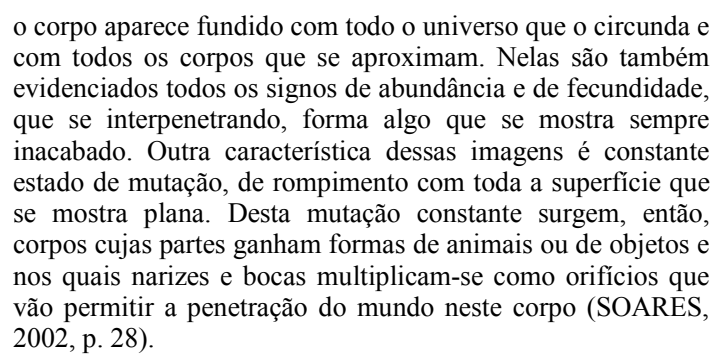

As práticas de cultura popular do Período evidenciavam um elemento central: a inversão topográfica do corpo e com isso, o que é baixo - órgãos genitais, excrementos - assumia um profundo sentido de ambivalência e regeneração. Apresentavam-se como um constante recriar do mundo e do próprio ser humano

\footnotetext{
${ }^{6}$ THINES, G.; LEMPEREUR, A. Dicionário de ciências humanas. Lisboa: Edições 70, [19--]. - A autoridade tradicional, no sentido weberiano, recebe sua legitimidade por herança. No contexto da sociedade medieval, a autoridade concentrava-se nas figuras do clero e da nobreza, notadamente o rei, sendo recebida diretamente de Deus.
} 
diferindo, radicalmente, do tipo de pensamento que iria, na Modernidade, desprezar tudo que diz respeito ao baixo ventre valorizando, em contrapartida, aquilo que é topograficamente alto, ou seja, a cabeça, local de comando do corpo.

Inserida na vida das comunidades, a arte popular constituía a dimensão de uma concepção estética da vida prática ${ }^{7}$ que cumpria um papel fundamental na forma como as pessoas se percebiam e se relacionavam entre si e com a natureza. Nessa concepção

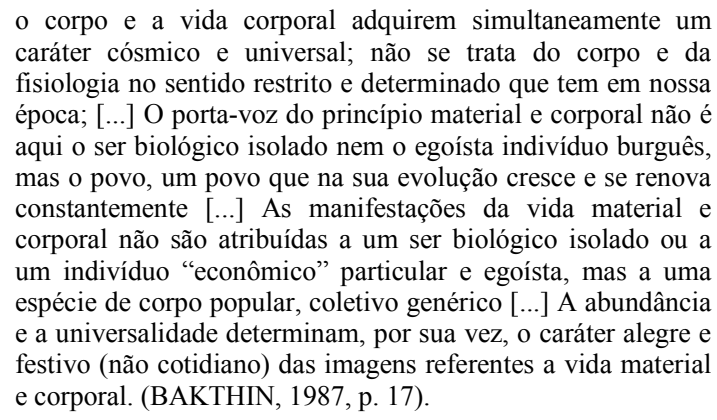

Conforme Sant`Anna (2001), não devemos desconsiderar que a concepção cristã hegemônica na Idade Média realizou uma separação entre o homem e a natureza. O cristianismo considera que a natureza e o homem são, igualmente, obras do mesmo Deus e por isso formam uma unidade, mas ao contrário das visões típicas do mundo antigo, o ser humano é visto como um ser dotado de uma alma imortal e, portanto, superior a natureza da qual deve tornar-se independente a medida em que caminha em direção ao Ser Supremo. As concepções cristãs gestadas na Idade Média, portanto, já delegam ao corpo um significado menor em relação ao espírito basicamente porque realizam, com clareza, a distinção homem-natureza. Diferindo das visões clássicas, a natureza para o cristianismo, "não é eterna e o homem não é um ser na natureza mas um ser diante dela.” (SANT'ANNA, 2001, p. 12).

O corpo aqui foi considerado domínio do terreno e parte da natureza devendo ser controlado em seus apetites e regulado em seus desejos em função do alcance da

\footnotetext{
${ }^{7}$ BAKHTIN, M. A cultura popular da idade média e no renascimento: o contexto de François Rabelais, São Paulo: Hucitec, 1987, p. 17. - Uma concepção, chamada por Bakhtin de realismo grotesco, que tem como aspecto fundamental a imagem grotesca do corpo que consiste em "exibir dois corpos em um: um que dá a vida e desaparece e outro que é concebido, produzido e lançado no mundo [...] Do primeiro se desprende sempre, de uma forma ou de outra, um corpo novo."
} 
realização espiritual. Já que a verdadeira essência humana era a sua alma, a pessoa devia elevar-se acima das necessidades carnais e mundanas e buscar a realização espiritual e ultraterrena. Porém, “o dogma cristão da ressurreição confere ao corpo a dignidade de participar da espiritualidade, pois, segundo ele, o próprio corpo se transfigura, tornando-se participante da natureza imortal do homem". (GONÇALVES, 1994, p. 47).

Embora tenha havido um rompimento com as visões clássicas acerca do homem e sobre o corpo humano ${ }^{8}$, o movimento da história ao acolher, ao mesmo tempo, rupturas e continuidades permitem perceber que se na Idade Média os valores e os usos do corpo se modificaram, eles também guardaram o registro de modos de ser, pensar e agir de diferentes épocas. E assim, durante todo o período medieval persistiram em embate com o cristianismo, práticas - especialmente, práticas curativas e ligadas aos divertimentos - e teorias explicativas do funcionamento corporal que tomavam como referência às analogias, típicas das civilizações clássicas, do corpo com o cosmo.

A respeito Sant'Anna (2001) relata que a teoria dos humores permaneceu até mesmo no período renascentista como referência maior para as práticas médicas, sendo que Leonardo da Vinci, em seu tratado de pintura, ainda compara as estruturas corporais (ossos, sangue, veias, coração, baço, etc) com as estruturas e condições da natureza (rochas, mar, rios, calor, frio, ar, etc.). A permanência desse tipo de sensibilidade, explicação e usos do corpo pode ser compreendida se tomarmos como parâmetro as condições materiais e políticas de vida nesse período.

Elias (1994) recorda-nos que na Idade Média as pessoas estavam inseridas em pequenos contextos coletivos - a família, a aldeia - que eram, por sua vez, guiados pela interpretação dos textos sagrados e/ou pela vontade da autoridade do rei ou do clero. Nesse contexto, a reflexão individual baseada na observação e no pensamento de cada

\footnotetext{
${ }^{8}$ A respeito, ver: SANT'ANNA, D. B. de. É possivel realizar uma história do corpo? e também SILVA, A. M. A natureza da physis humana: indicadores para o estudo da corporeidade, Campinas: Autores Associados, 2001. - Nesta visão, o homem está fundamentalmente imerso na natureza e o corpo humano é considerado como parte de uma rede na qual relacionavam-se as condições sociais, geográficas e históricas. É impossível, portanto, pensar o corpo separado e autônomo diante dos fenômenos naturais. $\mathrm{O}$ corpo é assimilado à estrutura cósmica em uma analogia que, apesar de assumir diferentes conotações ao longo do período clássico, reservava ao corpo um papel hierarquicamente semelhante a alma na definição do que é o ser humano.
} 
um sobre o mundo e sobre a vida tinha pouco valor. As indagações sobre o destino da alma imortal, sobre as possibilidades do homem e dos animais não eram respondidas pelo indivíduo que observava e pensava sobre isto. Ao contrário, as respostas só podiam ser encontradas com a ajuda

deste ou daquele tipo de autoridades reconhecidas, escrituras sagradas ou homens bem conceituados - em síntese através da revelação direta ou indireta. As observações individuais eram de muito pouca serventia e a reflexão individual só contribuía na medida em que se apresentasse como uma interpretação de uma das fontes de revelação. (ELIAS, 1994, p. 83).

Em função deste modo de vida, as pessoas

sentiam-se parte de um reino espiritual. Podiam sentir-se inseridas numa hierarquia de seres cujo patamar mais inferior era composto pelas plantas e animais, e o mais elevado, pelos anjos, tendo por ápice o próprio Deus. Ou talvez se vivenciassem como uma espécie de microcosmo cujo destino estava estreitamente ligado ao macrocosmo da criação. Qualquer que fosse sua forma particular, um traço básico deste panorama do homem e do mundo era que aquilo que podia ser percebido pelos sentidos adquiria significação a partir de algo que não podia ser percebido e confirmado pela reflexão individual nem pelas observações individuais. (ELIAS, 1994, p. 84).

Por outro lado, inseridas desde a infância em pequenos grupos humanos - dos quais eram, em grande medida dependente -, as pessoas não tinham "oportunidade, necessidade, nem capacidade de ficar sós" (ELIAS, 1994, p. 108), sendo seu comportamento constantemente adaptado e ajustado ao convívio com os outros. Por esse estreitamento da relação eu/nós, o controle do comportamento individual realizava-se pela presença - e às vezes, o medo - constante dos outros e pela consciência de estar a eles ligados pela vida inteira. Ou seja, o controle do comportamento da pessoa era externo efetivando-se quando necessário através de punições corporais, prática que foi sendo progressivamente condenada 9 .

\footnotetext{
${ }^{9}$ COSTA, J. F. Ordem médica e norma familiar, Rio de Janeiro: Graal, 1983. - afirma que a Companhia de Jesus, já sintonizada com as novas necessidades sociais, postulava a valorização e o culto ao corpo dos sacerdotes entendendo que os soldados de Cristo deviam ser fortes e saudáveis, condenando a imposição de castigos e penitências corporais e recomendando, inclusive, a prática regular de exercícios físicos.
} 
Apesar dos dogmas cristãos, não existia a necessidade de mecanismos tão intensos de autocontrole do corpo e de suas manifestações sendo possível, na maior parte das situações, vivencia-las como parte da totalidade humana, sem culpa, escrúpulo ou vergonha. Era possível uma vivência afetiva ampla que perpassava toda a rede de co-existência social onde não existia, com tamanha intensidade, a ocultação, tanto para os outros como também para si mesmo das funções, manifestações e pulsões corporais.

É também importante considerar, de acordo com Elias (1994), que o modo de vida dominante não promovia aos indivíduos muitas oportunidades de decisão, inclusive, sobre o próprio destino. A própria sobrevivência individual, encontrando-se se ameaçada por toda sorte de perigos e vicissitudes, tornava imperiosa a proteção e o controle do grupo sobre a pessoa e a identificação, quase automática, desta com os comportamentos, anseios, metas e ideais do coletivo. As pessoas - homens, mulheres e crianças - comumente tinham suas vidas definidas do ponto de vista do nós, ou seja, em função do bem estar da família ou da aldeia, vivendo estreitamento ligados às tradições e necessidades do grupo, seguindo um padrão típico de comportamento.

Quase sempre, homens e mulheres não tinham direito, necessidade e capacidade de escolher modos de vida diferenciados daqueles do grupo no qual se inseria tendo, diante de si, um único caminho a ser trilhado por toda a vida. Esse modo de vida não oportunizava o desligamento do mundo e/ou a fuga para si, típica de nossos dias e que é o produto da privatização da vida em, praticamente, todas as suas instâncias. Tal desligamento e/ou fuga foi sendo produzido ao longo do processo de desenvolvimento individual daqueles que vivem nos Estados nacionais modernas, nos quais o controle sobre a dimensão expressiva da corporalidade assume características de uma ditadura do comportamento, alienando de tal forma a pessoa de seu corpo que não é raro as manifestações, desejos e apetites corporais tornarem-se desconhecidos para ela própria.

O processo civilizatório ocidental proporcionou o surgimento de grandes formações sociais como os Estados nacionais que, por sua vez, ampliaram a mobilidade das pessoas pela estrutura social e promoveram a redução do papel das pequenas formações - família, aldeia, paróquia, entre outros - na definição do destino de cada um. Foi ocorrendo, nesse processo, o desligamento do destino de cada um do destino de todos, o que era garantido em outros períodos históricos pela ligação da pessoa com o 
pequeno coletivo onde nascia e se desenvolvia. A transição para a Modernidade realizou o relaxamento dessa tradição bem como a perda de poder das instituições que a mantinham. Ao mesmo tempo, que a rica cultura popular do Período - que tinha no corpo do artista a principal atração - também foi, pouco a pouco, sendo colocada como prática imoral e inconveniente a indivíduos e espaços civilizados ${ }^{10}$.

Elias ressalta que a concepção do ser humano como parte da natureza e como parte da criação divina perdeu a posição central e dominante na estrutura do pensamento humano. Em seu lugar, surgiu e desenvolveu-se a noção do indivíduo independente, autônomo e capaz de, isoladamente, compreender os eventos e acontecimentos da vida através da razão, único instrumento válido de conhecimento. O ser humano assumiu, na Modernidade, uma nova posição frente à existência. Dessa nova posição, a visão de homem é a de um ser capaz de, na condição de sujeito, ter acesso á compreensão tanto de si próprio quanto dos outros e da natureza. Como sujeito, considera que conhece pelos poderes da razão enquanto que a materialidade, destituída das possibilidades do conhecimento, é objeto a ser conhecido.

\section{A Observação e o Pensamento como Mediadores na Relação com os "Outros"}

René Descartes (1596-1650) foi o pensador que primeiro sistematizou essa nova autoconsciência retratando, paradigmaticamente, as principais dificuldades que ele e os homens de seu tempo enfrentaram ao perceberem-se como sujeitos do saber ao mesmo tempo em que se percebiam também como objetos do pensamento e da observação humanas. Refletindo sobre o indivíduo que pensava sozinho, livre e independente das autoridades, Descartes tentou responder à pergunta secular: quem sou eu? E sua resposta se resumiu no fato de que era sou alguém que pensa, um espirito pensante com

\footnotetext{
10 Pode-se notar, entretanto, as possibilidades de resistência dessa cultura uma vez que ela permaneceu ainda inteiramente viva e presente até meados do século XIX. É então que homens da ciência iniciam, de forma sistemática, um processo de apropriação de seus elementos, metamorfoseando-os em função da utilidade das ações corporais. Em especial, as artes circenses foram vitimadas por este processo sendo apropriadas e re-significadas pelos cientistas dos séculos XVIII e XIX e transformada no conjunto de preceitos e normas de bem viver que recebeu a denominação de ginástica, mais tarde, educação física. Ver mais em Soares, Carmem. Imagens da educação no corpo.
} 
o poder de duvidar e cujo corpo não era condição para tal, ou reproduzindo suas palavras do filósofo

eu Eu era uma substância cuja essência ou natureza consiste exclusivamente no pensar e que, para ser, não precisa de nenhum lugar nem depende de nada material. De modo que eu, a alma pela qual sou é inteiramente distinta do corpo e até mais fácil de conhecer que este e, mesmo que o corpo não existisse, ela não deixaria de ser tudo que é. (DESCARTES, 2002, p. 42).

Descartes, porém, entendia que tinha um corpo e que tal corpo tinha necessidades: que tinha fome, sede, dor. Ele reconheceu que o seu $e u$ estava de alguma forma unido a substância corporal formando uma unidade $e u$-corpo. Assim, percebeu que "a natureza [...] ensina [...] que não estou apenas alojado em meu corpo, como um piloto em seu navio, porém, mais que isso, a ele estou ligado muito estreitamente e de tal modo confundido e amalgamado, que me componho como um único todo com ele". (DESCARTES, 2002, p. 46).

Desse modo, o filósofo seiscentista reconheceu a existência do corpo, mas pensou-o, essencialmente, sob o ponto de vista de máquina capaz de captar do exterior o material de trabalho da res cogitans. O método da dúvida instigava-o a desconfiar das informações obtidas pelos sentidos e a considerar os órgãos sensoriais como uma fonte não confiável de acesso à verdade. Em sua análise das informações fornecidas pelos órgãos sensoriais evidenciou-se uma desconfiança quanto à verdade que elas informariam à alma pensante. A dúvida quanto a confiabilidade das informações sensoriais no processo do conhecimento revela uma questão mais ampla, ainda não respondida pelas filosofias idealistas e que está relacionada à concepção do homem como ser cindido em interior/exterior, dentro/fora, corpo/alma. Como é possível, eis a questão, que o sujeito cognoscente possa adquirir conhecimento verdadeiro dos objetos? Esse dilema foi objeto do pensamento de vários filósofos como Locke, Hume, Berkeley e Kant. 
Apesar dessa dúvida, a atividade dos órgãos sensoriais, principalmente a observação visual, foi reconhecida por Descartes, como a forma ${ }^{11}$ mais objetiva de obter conhecimento. Os órgãos sensoriais foram eleitos a parte do corpo que pode colaborar com a alma pensante na sua busca de conhecimento, o que retrata de forma paradigmática, a imagem do sujeito que tem no pensamento e na observação seus pontos de ancoragem e cujo corpo aparece como uma barreira que separa o mundo interior do mundo exterior, vale dizer, o eu dos outros, o indivíduo da sociedade.

O filósofo e metafísico seiscentista se descobria sozinho como sujeito que observava e pensava sobre a vida e sobre os homens, condição que possibilitava seu distanciamento do mundo das coisas animadas e inanimadas e sua identificação com o mundo não material. Por outro lado, ele compreendeu também que, na condição de ser observado pelos outros, fazia parte do mundo material e que tinha uma existência corporal. $\mathrm{Na}$ condição de objeto do conhecimento, organismo passível de ser reconhecido pelos órgãos sensoriais, o corpo foi entendido tal qual a máquina, em especial, o relógio.

Emergiu, assim, da reflexão cartesiana uma dupla visão de si mesmo. Ampliando sua consciência, o ser humano pela primeira vez na história percebeu-se, simultaneamente, como sujeito e objeto do pensamento. Tal visão encontrou na nova organização social que então se estruturava amplas condições para a consolidação de um tipo de autoconsciência e/ou autoimagem cuja essência é dada pela supervalorização da racionalidade. As transformações sociais que se operaram a partir do fim da Idade Média, refletindo-se nas formas de educação e nos estilos de vida das pessoas foi amalgamada pelo cogito cartesiano e impôs o crescente controle e restrição aos usos do corpo tendo em vista a sua utilidade.

Instaurava-se uma maior necessidade de observar e pensar antes de agir como condição para a inserção do indivíduo ao modo de vida e trabalho na sociedade capitalista. Ao impor essas restrições, a educação e o estilo de vida das pessoas

\footnotetext{
11 A respeito ver mais em DESCARTES, R. O discurso do método, São Paulo: Martin Claret, 2002. (parte v). Outra forma de alcançar o conhecimento diz respeito a idéias pré-concebidas como a idéias sobre Deus e a alma. Descartes rejeitou como meio de acesso à verdade, a imaginação e os sonhos.
} 
reforçaram a máxima cartesiana do indivíduo isolado de todas as pessoas e coisas e cindido por um muro invisivel que separa interior e exterior. E assim

$$
\begin{aligned}
& \text { o corpo, tal como aparece ao sentimento, separa uma pessoa } \\
& \text { da outra como uma parede, ainda que tenhamos perfeita } \\
& \text { consciência de que é também ele que as une. Parece um } \\
& \text { continente que isola o "exterior" e "contém" a própria pessoa, } \\
& \text { ou conforme o caso, a "consciência", os "sentimentos", a } \\
& \text { "razão" e a "consciência moral", como um receptáculo. } \\
& \text { (ELIAS, 1994, p. 99). }
\end{aligned}
$$

Considerada como função da totalidade do homem, condensada no conceito de inteligência, razão, cognição, ou ainda, espirito, a atividade de pensar apresentou-se ao ser que pensava como a atividade de uma substância não material localizada no interior do corpo humano.

\begin{abstract}
Os dois aspectos do duplo papel das pessoas em relação a si mesmas e ao mundo em geral - como conhecedoras de si e conhecidas por si, como experimentando a si e aos outros e sendo experimentadas por si e pelos outros, como desligadas do mundo na contemplação e indissociavelmente emaranhadas nos acontecimentos do mundo -, esses dois aspectos foram tão hipostasiados nos hábitos do pensamento e do discurso que se afiguraram objetos diferentes, como "corpo" e "mente", um dos quais se abrigava no interior do outro como o caroço numa ameixa. (ELIAS, 1994, p. 91).
\end{abstract}

Para Elias (1994), essa concepção exprime o grande problema da epistemologia clássica evidenciando-se em diversas teorias ${ }^{12}$ que, sem superar a distinção corpomente, sempre delegaram ao corpo e à sua atividade um significado secundário, porém, ao mesmo tempo aprofundaram a crença que dentro do corpo - portanto, ocupando um espaço, tal como o coração, os pulmões, a traquéia - vive o um eu interior e ele está só e separado dos outros. No contexto da relação indivíduo/sociedade, o eu que vive dentro do corpo, isolado e oculto, impedido de manifestar-se plena e genuinamente nas relações com o mundo - com as pessoas e as coisas - é visto como verdadeiro quando olhamos no espelho de nossa autoimagem.

\footnotetext{
${ }^{12}$ Quer tenham assumido uma forma empirista, inatista, racionalista, sensorialista ou positivista, as respostas à questão das relações entre o mundo interno e externo não chegaram a equiparar estes dois aspectos do humano e, portanto, não chegaram a propor a superação da distinção corpomente.
} 
Expressão concreta do individualismo, tudo o mais aparece tão somente como algo secundário e menos importante, inclusive o próprio invólucro onde habita essa essência. Elias (1994) afirma que o problema do muro invisível a separar o interior do exterior expressa-se, primeiramente, nas próprias questões que são colocadas pelas filosofias do século XX que tendem a se concentrar em questões que afetam o indivíduo isolado como a angústia, a morte, a dor, a solidão, principalmente, nos problemas da existência ou da experiência imediata da pessoa ${ }^{13}$. Raramente são colocadas questões referentes à existência de uma diversidade de seres humanos co-existindo coletivamente, mas privilegiaram as respostas e perguntas sobre o ser humano individualmente tomado. É como se o problema da coexistência dos seres humanos fosse acrescido, quase que acidentalmente, aos problemas do indivíduo. Porém,

Problemas como a solidão ou a "experiência direta", e como o (problema) do conhecimento, em que um "sujeito" isolado se opõe ao mundo dos "objetos" em sua busca de certeza, estão intimamente relacionados. A imagem não questionada do homem e noção de autopercepção subjacente a ela é essencialmente idêntica em ambos os casos. O filósofo [...] assume sua posição "no" indivíduo isolado. Pelos olhos dele, fita o mundo "lá fora" como que através de pequenas janelas; ou então medita, desse mesmo ponto de vista, sobre o que está acontecendo "do lado de dentro". (ELIAS, 1994, p. 101).

A dualidade subjacente a essa visão é responsável pela sensação, tão comum em nossos dias, de se estar sozinho mesmo em um mundo de pessoas e coisas. O corpo aparece como uma prisão ${ }^{14}$, uma cela de onde se olha e se pensa sobre o mundo externo; suas janelas e portas são os órgãos sensoriais através dos quais chegam as imagens, sons, cheiros e sabores do mundo; um mundo no qual o sujeito não se

\footnotetext{
${ }^{13}$ Considero importante aqui fazer referência à filosofia marxista que realizou um contraponto a essa tendência uma vez que a mesma toma a dimensão material da práxis social como ponto de partida para pensar o homem e a sociedade, apresentando a visão do ser humano como produto e produtor da sociedade onde se insere e cujos problemas são resultantes dos modos e formas como se organiza a macro estrutura social.

${ }^{14}$ Sintonizada com os eventos e concepções de seu tempo, a literatura, em especial, vem retratando esta sensação. Não é raro encontramos nas narrativas literárias a imagem do eu interior, genuíno, autêntico, porém, reprimido pelo mundo exterior. Conforme ELIAS, N. A sociedade dos indivíduos, Rio de Janeiro: Jorge Zahar, 1994, p. 87, a partir do século XVIII, "a atenção [dos escritores] passou a se concentrar não apenas na narração dos acontecimentos, mas em como as pessoas os vivenciavam. Os autores descreviam uma paisagem, por exemplo, e ao mesmo tempo a chamada "paisagem interior" [...] Descreviam encontros entre as pessoas e, ao mesmo tempo, o "fluxo de consciência" delas ao se encontrarem."
} 
identifica. À sociedade, por sua vez, é delegado o papel de carcereira, quase uma pessoa, que impede que o eu genuíno possa se manifestar. Educado para contenção e o controle do gesto, inserido na imensa teia de relações de poder existentes na sociedade, adestrado pela disciplina, o ser humano moderno vai aprendendo desde a infância a reconhecer-se como um piloto que, solitário e oculto, dirige o corpo-máquina. Aprende que há a necessidade de observar - principalmente olhar - e pensar antes de agir, desenvolvendo a imagem de si como ser cujas partes interior e exterior são isoladas por um muro invisivel. Cindido, fragmentado, separado em duas partes - para sempre e desde sempre - inconciliáveis, a pessoa vê crescer a sensação de solidão, simultaneamente, à capacidade de observar e pensar, de dentro, sobre o mundo lá fora.

Ao mesmo tempo, o indivíduo adentra na vida social não em pequenas formações sociais, como a aldeia, a paróquia, entre outros, mas em grandes formações como os Estados-nacionais que ampliam a mobilidade das pessoas pela estrutura da sociedade e promovem a redução do papel do grupo na definição do destino de cada um. As pessoas possuem, cada vez mais, a possibilidade e a necessidade de decidir individualmente e priorizando seus próprios interesses, qual ou quais caminhos irão seguir. Vai ocorrendo, nesse processo, o desligamento do destino de cada um do destino de todos, o que era garantido em outros períodos históricos pela ligação da pessoa com o pequeno grupo onde nascia e se desenvolvia.

Como resultado e em paralelo com o processo de individualização, consolida-se a idéia da separação entre o indivíduo/sociedade sendo que os seres humanos modernos, possuindo consciência desse isolamento, vivenciam-se como sistemas herméticos relacionando-se com o exterior. Como resultante dessa consciência cindida, o indivíduo vive a angústia da solidão, um estranhamento diante do outro no qual não se reconhece. Segundo Elias (1994), a sensação de vazio ou de isolamento vivenciada pelo indivíduo pode ser comparada a um muro invisível que existe entre uma pessoa e outra, entre o mundo interior de cada indivíduo e o mundo exterior representado pelos outros.

Esses dois mundos apresentam-se como inconciliáveis sendo fonte de angústia e desassossego, pois, isolados em um eu interior não temos capacidade de nos reconhecermos em relação com os outros na condição de sujeito coletivo - enquanto 
nós. O eu, afinal, não concebe a sociedade como nós, mas, simplesmente, como uma coleção de outros eus. De forma geral, "o sujeito do conhecimento, chamado pelos mais variados nomes nas diversas teorias do conhecimento, correspondeu a essa idéia. O modelo subjacente a ele foi o de um eu individual dentro de seu invólucro". (ELIAS, 1994, p. 95).

É, pois, o corpo esse sistema fechado, o invólucro onde está abrigado o eu verdadeiro e essencial de cada um. A dinâmica que constrói esse tipo de consciência de si enquanto ser dotado de uma ativa parte interior, a res cogitans que está oculta dentro de uma submissa parte exterior, a res extensa, encontra-se no contexto das relações sociais onde a pessoa insere-se ocupando aí uma determinada posição e assumindo determinadas funções. É no interior dos contextos de interdependência entre a pessoa singular e a multiplicidade de pessoas que formam a sociedade que podem ser encontrados as dinâmicas e processos que resultam na produção do indivíduo que se percebe como proprietário de um corpo onde habita o sujeito individual que conhece.

Dessa forma, no século XX a intensificação do papel do corpo individual para o exercício do controle social assumiu uma direção, no mínimo, inusitada, ao difundir a idéia - antes negada e até mesmo execrada - da busca do prazer corporal como condição para a felicidade ${ }^{15}$. A busca do corpo/prazer - reduzida, porém, à dimensão do erotismo - associada crescentemente às demandas atuais pela beleza corporal e por um tipo de elegância caracterizada pelo corpo esbelto - a mística da linha ${ }^{16}$ - revelam-se, verdadeiramente, como álibis para o exercício disciplinar cotidiano e obsessivo. O processo cvilizatório, especialmente, a partir da segunda metade do século XX,

\footnotetext{
${ }^{15}$ Esse processo ganha ênfase no século XIX e XX quando a administração da sexualidade emerge como o campo aonde se focaliza o olhar disciplinador. A respeito ver: FOUCAULT, M. A história da sexualidade 1: a vontade de saber, Rio de Janeiro: Graal, 1977.

${ }^{16}$ Denominação dada por Baudrillard ao culto, quase místico, à silhueta longelínea e esguia difundida como ideal de beleza e elegância, principalmente, feminina. A respeito ver: BAUDRILLARD, J. A sociedade de consumo, Lisboa: Edições 70, 1975.
} 
aprofundou o controle dos gestos, ritmos, posturas, mas avançou também na modificação das formas corporais.

De fato, a obsessão pelo ideal da linha, símbolo de beleza e elegância, exige a contínua vigília como também o registro contínuo do corpo e de seus apetites. Segundo Urry apud Bruhns, 2000, p. 93 "o corpo transforma-se em objeto ameaçador que é preciso vigiar, reduzir e mortificar para fins "estéticos", com os olhos vivos nos modelos emagrecidos". Em toda a dinâmica que, atualmente, conforma o indivíduo a essa sutil e profundamente eficiente rede de poder ocorre, até mesmo, a inversão da premissa básica do controle corporal efetivado nos séculos XVIII e XIX quando a economia de energias foi a máxima divulgada para produzir, ao mesmo tempo, o corpo forte e dócil. Atualmente, ao contrario, a obsessão pelo prazer e pela beleza vem exigir a liberação de energias como a condição para o bem-estar individual e social.

A sofisticação das técnicas disciplinares que atuam sobre a corporalidade indica o desenvolvimento de novos modos de controle da pessoa e novas e sérias repercussões para as relações sociais. Nesse sentido, é particularmente relevante a posição ocupada pela educação escolar na formação do indivíduo, inclusive, em função da importância crescente que a escola tem assumido tanto no projeto de dominação da burguesia quanto também naqueles projetos vinculados à busca de formas mais igualitárias de vida.

Concluindo, cito a parábola das Estátuas Pensantes, metáfora usada com maestria por Norbert Elias (1994, p. 96) para retratar a expressão dessa forma particular de autoconsciência, parece-nos interessante para a demonstração dos efeitos do muro invisivel sobre os modos como o indivíduo reflete sobre si mesmo e sobre o mundo. Eila:

À margem de um largo rio, ou talvez na encosta íngreme de uma montanha elevada, encontra-se uma fileira de estátuas. Elas não conseguem movimentar seus membros. Mas tem olhos e podem enxergar. Talvez ouvidos, também, capazes de ouvir. E sabem pensar. São dotadas de "entendimento". Podemos presumir que não vejam umas às outras, embora saibam perfeitamente que existem outras. Cada uma está isolada. Cada estátua em isolamento percebe que há algo acontecendo do outro lado do rio ou do vale. Cada uma tem idéias do que está acontecendo e medita sobre até que ponto essas idéias correspondem ao que está acontecendo. Algumas 


\begin{abstract}
acham que essas idéias simplesmente espelham as ocorrências do lado oposto. Outras pensam que uma grande contribuição vem do seu próprio entendimento; no final, é impossível saber o que está acontecendo por lá. Cada estátua forma sua própria opinião. Tudo que ela sabe provém de sua própria experiência. Ela sempre foi tal como é agora. Não se modifica. Enxerga. Observa. Há algo acontecendo do outro lado. Ela pensa nisso. Mas continua em aberto a questão de se o que ela pensa corresponde ao que lá está sucedendo. Ela não tem meios de se convencer. É imóvel. E está só. O abismo é profundo demais. O golfo é intransponível.
\end{abstract}

\begin{abstract}
The text to search to achieve the rescue of storical relation individual, society and body it present-day to using the concepts sociological Nobert Elias (1897-1990). O intent to demonstrate how the body education, especially in childhood, one-self how the privileged context for civilization in process, that impose, the individuals of society cortesy, the exercise of intense self-control of pulsation and necessity physical. The aprroach to relapse over the consequence, for the individual e social life, of understanding of human creature how creature to separete em out-side-inside, bodymind.
\end{abstract}

Key-Words: Body; Individual; Society.

\title{
Referências Bibliográficas
}

ANDRADE, C. D. de. Eu: etiqueta. In: Corpo. Rio de Janeiro: Record, 1984.

BAKTHIN, M. A cultura popular da idade média e do renascimento: o contexto de François Rabelais. São Paulo: Hucitec, 1987.

BAUDRILLARD, J. A sociedade do consumo. Lisboa: Edições 70, 1975.

BRUHNS, H. T. O corpo contemporâneo. In: BRUHNS, H. T.; GUTIERREZ, G.

(Org.). O corpo e o lúdico. Campinas: Autores Associados, 2000. p. 89-102.

COSTA, J. F. Ordem médica e norma familiar. 2. ed. Rio de Janeiro: Graal, 1983.

DESCARTES, R. Discurso do método. São Paulo: Martin Claret, 2002.

ELIAS, N. A sociedade dos indivíduos. Rio de Janeiro: Jorge Zahar, 1994.

FOUCAULT, M. A história da sexualidade: a vontade de saber. Rio de Janeiro: Graal, 1977.

GEERTZ, C. A interpretação da cultura. Rio de Janeiro: Guanabara Koogan, 1978. 
GONÇALVES, M. A SALIM. Sentir, pensar e agir: corporeidade e educação. Campinas: Papirus, 1994.

GUIRALDELli JR., P. O que é pedagogia. São Paulo: Brasiliense, 1996. HOBSBAWN, E. A Era das revoluções: europa (1789-1848). 15. ed. Rio de Janeiro: Paz e Terra, 2001.

MACHADO, R. Por uma genealogia do poder. In: FOUCAULT, M. Microfísica do poder. Rio de Janeiro: Graal, 1979. p. 05-23.

ROUANET, S. P. O olhar iluminista. In: BORGES, A. (Org). O olhar. São Paulo: Companhia das Letras, 1998. p. 125-148.

ROUSSEAU, J. J. Emílio ou da educação. São Paulo: Martins Fontes, 1999.

SANT'ANNA, D. B. de. É possível realizar uma história do corpo? In: SOARES, C. L. (Org.). Corpo e história. Campinas: Autores Associados, 2001. p. 03-23.

SEVCENKO, N. O renascimento. São Paulo: Atual, 1986.

SILVA, A. M. Corpo, ciência e mercado. Campinas: Autores Associados, 2001a.

. A natureza da physis humana: indicadores para o estudo da corporeidade. In: SOARES, C. L. (Org.). Corpo e história. Campinas: Autores Associados, 2001b. p. 2541.

Corpo, conhecimento e educação. In: SOARES, C. L. (Org.). Corpo e história. Campinas: Autores Associados, 2001. p. 109-129.

Imagens da educação no corpo: estudo a partir da ginástica francesa no século XIX. 2. ed. Campinas: Autores Associados, 2002.

THINES, G.; LEMPEREUR, A. Dicionário de ciências humanas. Lisboa: Edições 70, [19--]. 